\title{
Surrealismo, estética e ideología en El autómata de Xavier Abril
}

\author{
Luis Fernando Chueca \\ Pontificia Universidad Católica del Perú \\ Ichueca@pucp.edu.pe
}

\begin{abstract}
Resumen
Xavier Abril, luego de escribir una poesía muy vinculada a las vanguardias y en especial al surrealismo, declara hacia 1931 su convicción marxista y su abandono de los experimentos vanguardistas que representaban, según confesión propia, "una etapa ya superada por el autor". Es precisamente cuando se inicia el tránsito entre ambos momentos que Abril escribe la nouvelle El autómata, narración vanguardista con elementos góticos y fantásticos que puede leerse, a la vez, como crítica política de lo burgués y del capitalismo enajenante y cosificante. Este artículo busca situar a Xavier Abril y a El autómata en la encrucijada entre la efervescencia del vanguardismo y su abandono, así como en el nudo de la discusión estética-ideología en el inicio de los años 30 en el Perú.

Palabras claves: Xavier Abril, surrealismo, narrativa de vanguardia, estética e ideología.
\end{abstract}

\begin{abstract}
Xavier Abril, after writing poems closely linked to the avant-garde and especially surrealism, declares his Marxist conviction and his abandonment of avant-garde experiments representing, by his own admission, "a stage already outdated by the author". It is precisely when the transition between the two moments that Abril write nouvelle El autómata, modernist story with Gothic and fantastic elements, that can be read
\end{abstract}


both as political critique of the bourgeois and alienating and reifying capitalism. This article seeks to place Abril y El autómata as the crossroads of the effervescence of modernism and its abandonment, and the aesthetic-politics discussion in the beginning of the 30's in Peru.

Keywords: Xavier Abril, Surrealism, Modernist narrative, Eesthetics and ideology.

Recibido: 10/3/2015 Aceptado: 20/4/2015

\section{Xavier Abril, el campo literario peruano y la vanguardia interna- cional}

Algunos estudios sobre la vanguardia en el Perú (González Vigil 2004, Lauer 2001) identifican 1930 como un año de frontera. No porque propongan necesariamente el fin de esta en dicho año, sino porque representa un momento de diferenciación entre una primera etapa -la que se desarrolla en los veinte y, sobre todo, a partir de 1925 y 1926- de mayor agitación, polémicas encendidas e importantes proyectos que articulaban estrechamente perspectivas estéticas, ideológicas y políticas, y una segunda en que si bien sigue produciéndose una obra vanguardista de gran importancia, se ven debilitados los ímpetus de renovación estético-ideológica y muchos autores abandonan el entusiasmo por las renovaciones literarias y marchan hacia una mayor preocupación y acción política directas. En 1930 o, más precisamente, en el tránsito entre 1929 y 1931, la sociedad peruana atestigua varios hechos que revierten en lo mencionado. Por un lado, se deja sentir el impacto tanto del crack económico de 1929 y la consecuente Gran Depresión $\square$ que acaban con los "locos años veinte" $\square$, como de la mayor concentración de poder por parte de Stalin en la Unión Soviética tras la expulsión de Trotsky, que provoca un endurecimiento de las izquierdas en todo el mundo y favorece entre muchos artistas y escritores socialistas la asunción de posturas proclives al realismo socialista, que se convierte en política oficial en Rusia en 1932. Por otro lado, en el contexto interno peruano, con el final de la dictadura de Augusto B. Leguía y su proyecto modernizador de la Patria Nueva, en 1930, el endurecimiento político se agrava con el gobierno militar de Sánchez Cerro. En 1930, también, se produce la muerte de Mariátegui, el más importante animador de la vanguardia como proyecto estético-ideológico; a los pocos meses cierra Amauta y, casi en paralelo, el Boletín Titikaka del grupo puneño Orkopata. 
A propósito de la modificación de los ánimos en la escena literaria de avanzada, Luis Alberto Sánchez escribía en 1931: "Ningún poeta ha saludado el otoño. ¿Saludará alguno a este invierno inminente? Se han jubilado los poetas jubilantes, se han dado de baja los poetas polemizantes, y hasta los poetas sociales prefieren el combate directo. [...] A muchos los ganó la emoción política y la urgencia social" (30). Sin embargo, la "vuelta al orden" impulsada por la más decidida voluntad de acción política directa de esos momentos no acabó con los ímpetus vanguardistas. Disminuyó, es cierto, la voluntad de polémica y parecieron naufragar varios de los proyectos colectivos de renovación artística, pero se siguió produciendo, como señalé, aunque en menor cantidad, literatura de vanguardia, y se publicaron varios muy buenos libros, buena parte de ellos influenciados por el surrealismo, hasta que, en 1939, pueda considerarse cerrada la vanguardia histórica para el caso peruano, luego de la segunda partida de César Moro del Perú1.

Es en ese contexto de tránsito en que varios autores fueron abandonando sus convicciones vanguardistas, que el poeta Xavier Abril (Lima, 1905 - Montevideo, 1990) escribió la nouvelle El autómata2, entre 1929 y 30, y publicó su primer poemario: Hollywood (Relatos contemporáneos), en 1931. Luego, en 1935, apareció su segundo libro, Difícil trabajo. Antología (1926-1930), conformado, también, como Hollywood, por poemas de potente carácter vanguardista, pero que, según lo señala el autor en una nota incluida en las primeras páginas, "representa una etapa ya superada por el autor; debió publicarse en 1932” (Abril 2006: 110). Xavier Abril resulta, en ese sentido, como veremos, un personaje representativo del proceso reseñado líneas arriba.

Desde muy joven, Abril fue un entusiasta actor de la escena vanguardista peruana, publicando textos poéticos en revistas desde 1923. En 1926 viajó a Europa, en donde conoció de cerca el proceso de la modernización literaria en curso y a varios de sus protagonistas. Tomó contacto con Breton, Éluard y Aragon, quienes conocieron y celebraron algo de su obra3. Volvió al Perú en 1928

1 Moro viajó a México en 1938, pero El uso de la palabra, la revista de número único que editó junto con Emilio Adolfo Westphalen, apareció en 1939, el año en que Moro, además, terminó de escribir La tortuga ecuestre, que recién se publicó en 1958. Sobre la participación de Moro en el período final de la vanguardia peruana ver Chueca 2009: 107-113.

2 Aunque no la publica sino fragmentariamente: el capítulo "Lucha y pérdida del mundo" en Bolívar en noviembre de 1930. Otros fragmentos ("El silencio", "Origen y presencia del hombre" y "Metamorfosis de Sergio") aparecieron en homenaje a Abril que le dedicó en su número 9-10 la revista Creación y crítica en 1971, y finalmente se publicó íntegramente en Documentos de literatura 2-3, número dedicado a la "Narrativa peruana de vanguardia", en 1993. Se reeditó en el 2008 en El autómata y otros relatos, con estudio preliminar de Jorge Valenzuela. Es de esta edición de donde cito.

3 En Amauta 18 (octubre 1928) se publica una breve nota titulada "De 'Les feuilles libres"', firma- 
y participó más estrechamente en el proyecto de Amauta, publicando (reseñas, poemas, traducciones, declaraciones estéticas, comentarios sobre las literaturas europeas de vanguardia, etc.) en prácticamente todos los números desde su vuelta hasta la muerte de Mariátegui, además de contribuir activamente, como este, a la difusión del surrealismo en el Perú. A la vez, vinculó a Mariátegui con Carlos Oquendo de Amat, el autor de 5 metros de poemas y fue fundamental en el inicio del intercambio epistolar entre Breton y el ideólogo peruano. En 1930 regresó a Europa a participar como editor de la revista Bolívar que publicaba su hermano Pablo Abril de Vivero en España; en ella, de gran resonancia en el Perú y en la que estuvo muy involucrado también César Vallejo, aparecieron diversos artículos y comentarios suyos así como uno de los capítulos de El autómata, ese mismo año. Además colaboró con la revista inglesa Transition, dirigida por Eugene Jolas, en la que, entre 1927 y 1938, publicaron escritores y artistas como James Joyce, Gertrude Stein, William Carlos Williams, Ernest Hemingway, Samuel Beckett, H.D., Juan Gris, Max Ernst y Pablo Picasso, entre muchos otros, y fue coeditor de la revista trilingüe Front, editada en Ámsterdam por Sonja Prins.

A esos años corresponden también dos artículos suyos - "Estética del sentido en la crítica nueva", en junio de 1929, y "Palabras para asegurar una posición dudosa”, en julio de 1930 - que han sido calificados por Yazmín López Lenci como textos manifiestarios (1999: 102-105), y un tercero, "Nota a la muerte de la novela" (noviembre-diciembre de 1929), publicado como comentario a una declaración de Eugene Jolas y otros escritores en Transition 18, titulada "La novela ha muerto. Que viva siempre la novela". Este texto de Abril, como los dos anteriores, podría verse también como un manifiesto estético-ideológico y resulta de utilidad cotejarlo con El autómata. Sobre ellos volveré luego.

La revisión anterior permite formarse una idea acerca de la importancia de la figura de Abril hasta inicios de los treinta en el proceso de la renovación estética en el campo literario peruano. Xavier Abril, junto con poetas como Oquendo de Amat, Enrique Peña Barrenechea, Adalberto Varallanos y Westphalen, formó parte de un núcleo muy dinámico (una formación literaria en términos de Raymond Williams) que entre mediados y finales de la década de los veinte e inicios de la siguiente exploró las posibilidades de un surrealismo hondo y no formulista, con gran apertura hacia otras corrientes, poco antes, incluso, de que cobrara importancia capital en ese ámbito la figura de César Moro. Paralelamente, su poesía -la que se iba conociendo en revistas- trabajaba nuevas posibilidades que fueron atendidas con interés por algunos de sus

da por Breton, muy elogiosa de la poesía de Abril (en particular del conjunto todavía inédito Taquicardia). 
contemporáneos, lo mismo que su ímpetu por hacer conocer caminos todavía no transitados en el Perú. Sabemos, por confesión de Westphalen, que Abril

... espíritu cordialísimo y abierto a todas las innovaciones [...], me dio [...] la prueba de que la poesía en prosa no era coto vedado de un Baudelaire o un Rimbaud y que todas las licencias estaban disculpadas en poesía siempre que no fueran incurridas por sí mismas sino en aras de exigencias rigurosas de la expresión poética. Por él empecé a familiarizarme con el Work in progress de Joyce y fue él quien intervino para hacerme publicar en Bolívar y en Front" (1996: 142).

Sin embargo, hacia el segundo lustro de los treinta, cuando Abril escribe el conjunto poético épico-político Declaración en nuestros días4, y en 1937, cuando publica Descubrimiento del alba, en el inquieto y renovador poeta "los hallazgos vanguardistas han sido decantados, interiorizados o purificados" (López Degregori 2010: 56). Los poemas que trabaja a continuación (a finales de los treinta), que publicará muchos años después, en 1987, bajo el título de La rosa escrita, retoman incluso las formas clásicas de la tradición española. Las páginas que siguen buscan situar a Xavier Abril y a El autómata en la encrucijada entre la efervescencia del vanguardismo y su abandono, así como en el nudo de la discusión estética-ideología en el inicio de los años 30 en el Perú.

\section{Estética e ideología (I)}

En "Autobiografía e invención", uno de los textos que abren y presentan Hollywood5, Xavier Abril explica el recorrido que lo llevó desde sus tempranas experimentaciones literarias en Lima y su viaje inicial a Europa, donde participó de los debates del cenáculo surrealista, hacia sus convicciones en los momentos de la publicación del libro, las que comenta diciendo que:

... a mi vuelta al Perú (1928) me ganó la revolución, el marxismo, en la prédica de Mariátegui. Y mi vida y mis esperanzas son el proletariado. No creo en otra clase para la continuación creadora del mundo. Mariátegui acaba de morir; pero mi vida está hoy como nunca ligada a su trabajo, a su orden social revolucionario. Mariátegui ha creado una conciencia, un nuevo nacimiento de América. Mi conocimiento y revelación del mundo político están vinculados a su agonía (20-21).

A continuación, aparece "Postbiografía o constatación presente", texto probablemente escrito en el mismo momento, que refuerza lo citado:

4 Publicado recién en 1988.

5 Los otros son "Notice", "Aclaración y esperanza" y "Posbiografía o constatación presente".

LETRAS 86 (123), 2015 
... ya he pasado la etapa de la desesperación suprarrealista. He nacido revolucionario. Pero solo ahora estoy ordenando mi sentido político dentro del marxismo. Todas las demás especulaciones carecen de vitalidad histórica. Conozco los vicios psicológicos de mi clase. Lo más terrible -realista y patético- que he sufrido en los últimos años ha sido la constatación de proceder de un cuerpo muerto. En esta auscultación he sentido toda la pureza de mi nuevo nacimiento (25).

Si consideramos que la muerte de Mariátegui acaeció en abril de 1930 y que el pie de imprenta de Hollywood es de enero de 1931, Abril debió escribir ambos textos (el primero con toda seguridad) entre abril y finales de 1930, a su regreso a España. Son dos los aspectos que aborda en los fragmentos citados: el reconocimiento de su filiación surrealista -aunque aparentemente dejada atrás o cuando menos ya no "en la etapa de la desesperación"-, y la declaración de su nueva convicción socialista (su acercamiento al marxismo y a la revolución proletaria), asumida a partir de su vuelta al Perú en 1928. A pesar de la separación discursiva operada entre ambas profesiones de fe, parece no haber todavía, en otros textos del mismo año 30 o del anterior (por ejemplo los dos manifiestos aludidos páginas atrás o la "Nota sobre la muerte de la novela"), la posibilidad de distanciarlas. ¿Qué sucede, en este camino, con El Autómata, escrito entre 1929 y 1930 ? Muchos de los rasgos de esta nouvelle permiten identificarla inequívocamente con la estética surrealista: desde los más fácilmente perceptibles, como cierto uso del automatismo en las imágenes, el flujo de conciencia, la dislocación de la causalidad racional y de la sintaxis, la discontinuidad y la fragmentación, o como el trabajo con los tópicos de la locura y el sueño, hasta los más enraizados en lo ideológico, como el combate contra la razón burguesa, aspecto en que el surrealismo podría tender un puente hacia el socialismo. Pero, ¿existe aquí realmente ese puente?, ¿de qué surrealismo se trata en este caso?

El propósito en lo que sigue es, en ese sentido, evaluar cómo se inscribe El autómata en ese tránsito que va desde un vanguardismo decididamente antiburgués pero de poca densidad política -como el que puede observarse en los poemas6 surrealizantes o claramente surrealistas de Hollywood7 o el de buena

6 Se trata de poemas (en prosa la mayoría), y el mismo Abril se refiere al conjunto de lo publicado como su trabajo poético. Sin embargo, el subtítulo del libro, Relatos contemporáneos, y la posibilidad de leer varios de los textos, efectivamente, como narrativos, llevaron incluso a que se comentara el libro como una novela, tal como lo hizo Carlos Cueto Fernandini.

7 Que corresponden al vertiginoso viaje de un flâneur universal opuesto a las visiones rígidas y estrechas de la razón instrumental y el pensamiento conservador y abierto a todas las posibilidades de gozo y disfrute que pueda ofrecer un mundo (real o imaginario) visto como cantera de posibilidades. Los conjuntos de poemas que incluye fueron escritos entre 1923 y 1927. 
parte de Difícil trabajo8- hacia las nuevas convicciones declaradas. Para dicha evaluación será necesario revisar las principales propuestas de Abril en los tres textos manifestarios mencionados más arriba.

En "Estética del sentido en la nueva crítica", que Abril anuncia como "Apuntes literarios de un libro sobre el Surréalisme en preparación" (1929a: 49), son dos los aspectos más destacables. El primero es el interés de los surrealistas por Jacques Vaché, "exaltado, criminal nato, jugador, vagabundo, ladrón de bancos, opiómano que pretende revelar en estas lamentables disidencias, valores morales de primer orden" (50). Abril señala que el signo fundamental de Vaché fue su condición de insatisfecho empedernido, lo que provocó su llamado constante al mal y lo llevó hasta borrar su propia existencia y anularse en la pura destrucción, en la locura y el crimen. Ese heroísmo de la insatisfacción -aun mayor que el de Rimbaud a juicio de Abril- lo habría hecho seguir vivo en "los más audaces intérpretes del espíritu del orden nuevo" (51), como Breton, quien reconoció su deuda enorme con él9. El otro aspecto importante es el trazado de una genealogía de la "inquietud estética" contemporánea que nace con el simbolismo ("el romanticismo -señala- luchó solamente por la imposición del sentimiento en el arte”, 51), pasa por las revoluciones del futurismo, cubismo y dadaísmo, y llega al surrealismo como "verdadero círculo totalizador de las direcciones antes nombradas, [que] señala ya en el mundo la orientación más fuerte del arte" (51). Añade que la seguridad y realización que alcanza el surrealismo radican en la conjunción de la teoría freudiana con "su adhesión en política a la fe marxista, a la revolución comunista" (51), aunque esto no implica suscribir un arte de propaganda neta y exclusivamente social. No hay que olvidar que Abril escribe esto en 1929, es decir después de la afiliación de Breton, Péret, Éluard y Aragon al Partido Comunista Francés, ocurrida en 1927.

Por su parte, la "Nota a la muerte de la novela" (1929b) es un comentario a una declaración de aquellos escritores a quienes menciona elogiosamente como "los pilotos surrealistas de Transition", titulada "La novela ha muerto. Que viva siempre la novela" y transcrita en ese mismo número de Amauta. En su texto, afirma Abril que lo que ha muerto en la novela "es la técnica, su funcionamiento cardiaco, debido al choque con un nuevo estilo de la vida" (70) y recalca que esa brecha se corresponde (a diferencia de lo que piensan los reaccionarios) con un nuevo momento histórico, en el que la Revolución Rusa,

8 De un onirismo oscuro, reverso interior y perturbado de las búsquedas de Hollywood, que revela los abismos y temores a los que el sujeto en pos de una liberación individual plena se asoma inevitablemente, aunque, también, como ha señalado López Degregori, presenta "varios textos que revelan una conciencia social y que se proponen como antídoto al encierro y aislamiento" (2010: 66). Los poemas de Difícil trabajo fueron escritos entre 1925 y 1929.

9 Y relevó la figura de Vaché en Los pasos perdidos de 1924.

LETRAS 86 (123), 2015 
por ejemplo, es un evento crucial. Por ello no basta -apunta- con constatar la defunción de la novela, sino que debe reconocerse igualmente el nacimiento de un nuevo organismo: "[e]xiste verdaderamente -y esto es una felicidad- un cuerpo nuevo, sin bacilos, sin los vestigios de la diabetes de la cultura antigua. Todos sabemos que la diabetes es una enfermedad específicamente burguesa" (70).

Finalmente, en "Palabras para asegurar una posición dudosa" (escrito poco antes de salir de nuevo del Perú y publicado en Bolívar 12 en Julio de 1930), lo que persigue Abril es hacer una presentación de la nueva poética a un público aparentemente algo ajeno a ella10. Para ello, explica las ambiguiedades del término vanguardia, con sus usos descalificadores y mistificadores, y ubica la poesía nueva como propia de un mundo que ya es otro y está alejado, en poesía, de la tradición de las audiciones musicales. El aspecto de este texto que más interesa al presente trabajo surge a partir de la relación que establece Abril entre la poca receptividad de la poesía nueva en el medio limeño y la existencia de una realidad burguesa que solo produce "autómatas":

La burguesía y sus vicios han tornado a sus seres en autómatas de la especie. [...] El verdadero panorama de la cultura burguesa -agónicaes terrible. De esta agonía ha nacido y se ha salvado una clase, que es el surréalisme; una clase y no simple y solamente una escuela literaria [...]; de este caos -hoy surréalisme- está naciendo un nuevo cuerpo, humano y maravilloso. Le está naciendo al mundo su verdadero cuerpo. La revolución materialista de nuestra época -es bueno que lo sepan los idealistas- va más allá del cuerpo en lo que este pueda significar de realidad pútrida como en el naturalismo burgués de Zola, que no excede [...] a las carnes descompuestas de las carnicerías. La realidad burguesa -más que en el nacimiento- está inspirada en la muerte, en la descomposición, en lo fatal del misterio. Es necesaria una sociedad comunista que reivindique el alba, el nacimiento y la alegría. (1930: 6-7)

Para terminar, luego de mencionar a los escritores y artistas con los que se siente identificado ("los mejores mozos de mi generación" los llama11) anunciando que seguirá luchando por un nuevo orden en la política y en la estética.

Como se observa -matices más, matices menos- en los tres textos, Abril establece una relación estrecha entre los más avanzados caminos de la reno-

10 Lo que seguiría a esta presentación sería la lectura de poemas en la Sociedad "Entre Nous"; la lectura fue impedida por la censura eclesiástica del arzobispado de Lima.

11 Se refiere a Martín Adán, Adalberto Varallanos ("muerto prematuramente cuando los mejores europeos principiaban a admirarle”), Oquendo de Amat, Enrique Peña Barrenechea, José Varallanos, Emilio Adofo Westphalen; los críticos Estuardo Núñez y Aurelio Miró; los pintores Juan Devéscovi y Camilo Blas. 
vación estética, por un lado, y la apuesta por la superación de la sociedad y la cultura burguesas a través de la vía del socialismo y la revolución, por el otro. La literatura, en esa medida, sin convertirse en propaganda y sin perder de vista la lección aprendida de la insatisfacción frente a la realidad circundante, debe reconocer no solo cuáles son caminos viejos, sino también -y quizá sobre todo- los verdaderamente nuevos. Esa oposición entre lo viejo y lo nuevo (en arte y en política), además, es representada insistentemente por Abril a través de la metáfora corporal, que le permite recalcar la perspectiva materialista frente a la idealista: cuerpos muertos y en descomposición frente a cuerpos nuevos y al nacimiento de lo verdaderamente humano y maravilloso.

Abril, en este sentido -tal como lo afirmara en "Autobiografía e invención" o como lo corroboran su constante colaboración con Amauta y su asidua y activa asistencia, mientras estuvo en Lima, a las tertulias en casa de Mariáteguidesarrolla sus posturas estético-ideológicas, en este período, cerca del pensador peruano. Y así como para Mariátegui la convicción vanguardista12 no será ya considerada un indicador suficiente cuando evalúe necesarios los deslindes definitivos entre revolución y decadencia, por lo que sostiene que el proyecto de Amauta debe definirse -al igual que la revolución- como fundamentalmente socialista13, para Abril ni el vanguardismo (término que consideraba equívoco, como vimos) ni el surrealismo le permitirán explicar el eje nuevo de sus convicciones. Es por eso, podemos suponer, que siente indispensable referirse a la superación de esas perspectivas luego de su adscripción al socialismo y a la revolución, a pesar de que sus textos de ese momento (como El autómata, por ejemplo) evidencian lo enraizado que sigue el sigue el surrealismo en su escritura y, en esa medida, en su visión del mundo.

\section{El autómata: locura, encierro y recusación de la sociedad burguesa}

El autómata nos acerca a la historia de Sergio, un loco encerrado en un manicomio, donde vive -o muere: agoniza- luego de haber sido internado allí por su padre, un alcohólico burgués (pequeño burgués, probablemente) que prácticamente lo ha abandonado allí. No conocemos las razones concretas de

12 Que representaba una amplia corriente que involucraba a todos aquellos que podrían aportar, de un modo u otro, con la creación de un Perú nuevo dentro de un mundo nuevo, por ejemplo a través de la recusación del hispanismo literario y del rechazo de la oligarquía o de las conformistas y estrechas mentalidades burguesas

13 Ver "Arte, revolución y decadencia" (1926) y "Aniversario y balance" (1928) de José Carlos Mariátegui, textos de apertura, respectivamente, de los números 3 y 17 de Amauta. Mariátegui siguió muy interesado y escribiendo muy lúcidamente sobre el surrealismo hasta momentos muy cercanos a su muerte. 
su encierro (más allá de la afirmación -asumida como verdad- de su locura) ni cuándo se produjo este. La nouvelle tampoco desarrolla una historia convencional que nos presente de modo transparente las desventuras del personaje en su cautiverio, sino que nos sumerge violentamente en el distorsionado y agónico tránsito de Sergio hacia su degradación y su muerte: un espantoso camino de enfermedad, delirio, miedos y dolor. Aunque podría reconstruirse una cierta linealidad básica en la narración, la percepción de esta se ve interrumpida por la tenue vinculación temporal o causal entre los capítulos, enunciados por una voz narrativa que recurre parcialmente al flujo de conciencia 14 , y por las constantes focalizaciones desde la subjetividad dislocada y delirante del protagonista, a través de la cual nos aproximamos a sus agudizadas sensaciones, fragmentos de sueños y pensamientos, alucinaciones y destellos de recuerdos.

Estos procedimientos narrativos -que podrían hacernos pensar en un vertiginoso trabajo de montaje cinematográfico- junto con cierto automatismo en la composición de las imágenes, han llevado a los (todavía muy pocos) comentaristas de El autómata15 a afirmar, oportunamente, su raigambre vanguardista-surrealista (con conexiones importantes con el horror gótico y la narrativa fantástica). Se ha señalado acertadamente, en este sentido, que con El autómata, Abril se enfrenta radicalmente a las concepciones de la novela burguesa, operando esta oposición simultáneamente en el plano de la composición textual y a través de la temática que desarrolla16. Se podría suponer que, de haberse publicado El autómata en los años de su escritura, hubiera contribuido decisivamente en la gestación de un nuevo tipo de lector de narrativa.

La principal razón temática para la afirmación de la confrontación de El autómata con la mentalidad y las prácticas burguesas corresponde al diseño de su protagonista, Sergio, como un autómata17: un despojo humano del mundo

14 Esto quizás explique la dedicatoria de la novela a James Joyce.

15 Zavaleta 2002, Valenzuela 2008, Elguera 2009.

16 Valenzuela escribe que Abril lleva adelante "el proyecto de una narrativa crítica antiburguesa apelando a los recursos de una prosa que, sin duda, renuncia totalmente a los modos del realismo, destruyendo aquello que es central en su praxis, esto es, el respeto de la razón, el ejercicio de la lógica naturalista. (2008: 23). Por su parte, Elguera señala que "[d]e hecho, no se trata del modus operandi de la novela clásica burguesa: en este universo textual el hacer y mentalidad que ella implica se diluyen en la narración: todo lo burgués es superado en el texto" (2009: párr. 39).

17 En un sentido cercano a la tercera acepción que ofrece el DRAE: "persona estúpida o excesivamente débil, que se deja dirigir por otra" "persona que se deja dirigir por otras" (1927). Valenzuela en primer lugar -y Elguera coincide- han discutido adecuadamente la interpretación de Lauer (2003) que habla de Sergio como una máquina que en el transcurso de la novela va siendo humanizada. 
deshumanizante de la modernidad capitalista. Así, para Jorge Valenzuela la figura de Sergio simboliza "a aquellos sujetos que para Abril encarnaban los vicios de la burguesía, aquellos que expiaban en 'los bancos, clubs, teatros, asilos y prostíbulos' la condición de enajenados por el dinero; de hombres saturados de soledad, de desamor; de víctimas aniquiladas por la ansiedad, por el alcohol, por la vanidad, excrecencias de un sistema individualista" (2008: 15); de este modo Abril pretendería contribuir a "demoler los valores de la burguesía describiendo la condición errática y desintegrada de los retoños de esa clase social" (24). Chirstian Elguera, por su parte, afirma que, con El autómata, Abril dirige su crítica a la modernidad en tanto concibe "el Progreso como nueva enfermedad de la civilización” (2009: párr. 1); la deshumanización consecuente, anota, convierte al hombre en un engranaje, un esperpento o un objeto numerado: un hombremasa, un ser sin voz manejado desde fuera (lo que se refuerza con el hecho de que, efectivamente, en El autómata, no conocemos ni una sola palabra pronunciada por Sergio). Estas interpretaciones, cercanas entre sí, parecen reforzarse a la luz de la afirmación de Abril, en "Palabras para asegurar una posición dudosa", de que la cultura burguesa funciona como una fábrica de autómatas:

Lo que hay ahora son autómatas de la realidad burguesa. Donde se pone el ojo se da uno con estos autómatas. Ya en la organización capitalista: en los bancos, clubs, hoteles, teatros, asilos o prostíbulos. La burguesía y sus vicios han tornado a sus seres en autómatas de la especie. El orden maquinístico está también en manos de autómatas. (1930: 6)

Como se ve, Sergio es propuesto, en dichas interpretaciones, como un personaje que encarna los vicios de la burguesía o representa al hombre-engranaje de la sociedad capitalista. Al respecto, propongo que es necesario discutir esta imagen a partir de determinadas descripciones y comentarios que, sobre él, desliza el narrador, aunque un tanto oscuramente (como es esperable en el marco de una narración vanguardista-surrealista cuyo lenguaje polisémico y cargado de poeticidad puede llegar a ser contradictorio y muy hermético a momentos). Veamos.

En primer lugar hay que recordar que también el padre de Sergio también es caracterizado como autómata en el capítulo inicial de la novela:

Su corazón tarado ya no lo oye. Su caminar es la [sic] de un hombre que no tiene ninguna responsabilidad. Es un autómata de la especie, del inconsciente. Su esqueleto también vaga dentro de él, de tal manera que el menor movimiento de huesos lo exaspera. (2008: 35)

El hecho de que la nouvelle se inicie con un capítulo (titulado "El padre y el hijo loco") en que el padre alcohólico es mencionado como autómata y es descrito con rasgos que serán retomados luego al hablar de su hijo (la enajenación, la aparente desconexión entre el sujeto y su estructura ósea, por 
ejemplo) pareciera sugerir que es la misma causa la que ocasiona la pérdida de humanidad de ambos, o que el hijo es un autómata porque ha heredado esa condición de su padre. No obstante, mientras que el padre es representado en este capítulo como alguien instalado en la sociedad burguesa (la cena en un restaurante, el vino, la caja de puros, los gestos de cortesía fingida con el mozo que lo atiende y su individualismo extremo así lo sugieren), quien, a pesar de su enajenación y su irresponsabilidad, tiene capacidad para desempeñarse de modo aparentemente adecuado en la vida pública (el mozo, como se menciona, no sospecha la turbia realidad que lo envuelve), Sergio -de quien, como anoté, solo sabemos que está encerrado porque es, o está, loco- aparece como desecho de esa misma sociedad que, además, debe mantenerlo encerrado (para su padre es necesario olvidarlo) para lograr su mejor funcionamiento18. Podría suponerse, por supuesto, que Sergio fue tan funcional a la sociedad burguesa como su padre y que llegó a un extremo de enajenación tal, que ya no pudo ser más parte de la máquina social; sin embargo, "el hijo loco" parece encarnar, más bien, una oposición a la visión del mundo y la moral burguesas. Refiriéndose a él, por ejemplo, dice el narrador:

¿Cómo podría encontrarle [a Sergio] antes de vivir, cómo antes de muerto? ¿En dónde, en qué grado desviado de este mundo tiritante, escurridizo? ¿Por qué ruta que no sea lágrima del aire, podría encontrar sus ojos? ¿Por dónde seguirán torcidos fraguando soles y otoños? Yo iría a un país desconocido a buscar sus palabras, para pronunciarlas en la primera inocencia de las voces maternas. (46-47)

Después de haber caído el hombre ¿espera, quizás, alguna nueva revelación? (57)

[Sergio] Es el olvido del sueño en el mundo. El cauce -regato con sol- de lo virginal que no encuentra los senos ni las manos. No podrían llegarnos las mañanas si a Sergio no le ocurriera todo esto. Tal vez se quedaran en esta frustración por llegar como pájaros heridos que sangran al alba. Con Sergio vienen desnudas, nada tímidas, las mañanas eróticas del muerto. (48)

Entre el negror y un vago mundo desdentado, huesoso, espín, nace el erizo. El hombre siente -entre las sustancias- su propia germinación. Así se da nuevamente al mundo. (52)

No seré un futuro turista del infierno. El pobre Sergio la pasó muy mal en su osadía. Allá él, que pague sus culpas de alucinado vagabundo del sueño. (57-58)

18 Es lo que se sugiere al inicio del último capítulo, "La ciudad y el manicomio": "Vive la ciudad del manicomio. No podría vivir sin ese panorama gris, enfermo de listones obscuros, enajenados" (66). 
Mejor no auscultéis el vacío de Sergio. Sus venas están llenas de aire, de la brisa de las eras. Cuidaos de las corrientes bandoleras que se ocultan en sus ojos: rayos voraces, devastadores. (61)

Retroceded ante este cuadro [de los ojos sombríos de Sergio], si no queréis perder la vida como Sergio la perdió viéndola, como hay que perderla, viéndola. (61)

Sergio [...] que vivió hasta asilar el relámpago en sus ojos. (62)

Los fragmentos citados dan, por cierto, una muestra de la prosa polisémica de Abril, de significados a ratos muy oscuros y hasta contrapuestos, pero creo que permiten vislumbrar en Sergio cierta condición de rebelde frente a la sociedad burguesa. Él parece dibujarse en estas citas como un transgresor: es "turista del infierno" o "vagabundo del sueño" cuyos ojos ocultan rayos devastadores o asilan los relámpagos; propicia la llegada de las mañanas eróticas. El narrador por ello advierte a sus interlocutores sobre la necesidad de cuidarse de los riesgos que representa su actitud, pero a la vez afirma que, así como Sergio, hay que perder la vida viéndola 19. Y "viéndola", en esta frase, parece remitir a la capacidad de visión (condición de vidente) o al tipo de revelación mencionada en el primer fragmento citado. Confluyen en Sergio algo de profeta, de maldito o de víctima propiciatoria. A partir de esto es posible proponer que en el diseño de este fracturado y agónico personaje hay rasgos que lo emparentan con Jacques Vaché -quien para Abril, como vimos, encerraba, con su irremediable insatisfacción, la voluntad de alcanzar "valores morales de primer orden" (1929a: 50) - o con Nadja, la protagonista del texto homónimo de Breton, cuya constante dinámica de desplazamiento, desapariciones repentinas y sorpresa permanente, así como cierta inaccesibilidad y su pensamiento otro abren vías que deben ser necesariamente reprimidas por la sociedad burguesa, por lo que es encerrada finalmente en un manicomio. Algo semejante puede entreverse en esas escurridizas pero fundamentales caracterizaciones que el narrador hace de Sergio. Se puede proponer, a partir de esto, que su condición de autómata no se debe a su 'locura', sino (el matiz es indispensable aquí) a su diagnóstico como loco y a su consiguiente encierro20. Lo que lo convierte en

19 Hay en diversos pasajes de El autómata cierto tono de sanción moral a Sergio. Pareciera que el narrador, asumiera, en su voz, en esos momentos, la perspectiva de la sociedad burguesa, con propósitos enfatizadores o irónicos, o como evidencia de las contradicciones internas del propio narrador.

20 La locura, señala Foucault en "La locura y la sociedad", es, en primer lugar, lo excluido; aquello que la sociedad separa (la locura/ la no-locura) porque no puede ajustarse a las normas propuestas por ella. En el caso de la locura, añade, son los cuatro sistemas fundamentales de exclusión los que se activan: son catalogados como locos aquellos que, simultáneamente, no pueden / quieren participar de esos sistemas: que no se pueden integrar en una dinámica productiva, rechazan las reglas de la moral familiar, no son escuchados porque su verdad es irresponsable y resultan marginales en los juegos. 
autómata, entonces, no es la "osadía" de su asomo al infierno o su navegación por los sueños, sino los controles que se le infligen, los tratamientos de que es objeto, el abandono al que es sometido; todo ello va destruyendo su voluntad transgresora y termina matándolo (¿termina matándolo?) luego de una férrea y dolorosa lucha como se desprende de los capítulos "Lucha y pérdida del mundo" y "Muerte del autómata".

Los manicomios o los hospitales psiquiátricos, dice Foucault, buscan encerrar "a todo un conjunto de individuos a los que llamaríamos en nuestro vocabulario individuos asociales, que tienen como rasgo común el ser obstáculos, estorbos en relación con la organización de la sociedad según las normas económicas formuladas en esa época. Aparece un internamiento esencialmente económico" (1999: 13). Algo semejante había escrito Antonin Artaud, en 1925, en el número 3 de La Révolution Surréaliste:

El hospicio de alienados, bajo el amparo de la ciencia y de la justicia, es comparable a los cuarteles, a las cárceles, a los penales.

No nos referimos aquí a las internaciones arbitrarias, para evitarles las molestias de un fácil desmentido. Afirmamos que gran parte de sus internados -completamente locos según la definición oficial- están también recluidos arbitrariamente. Y no podemos admitir que se impida el libre desenvolvimiento de un delirio, tan legítimo y lógico como cualquier otra serie de ideas y de actos humanos. La represión de las reacciones antisociales es tan quimérica como inaceptable en principio. Todos los actos individuales son antisociales. Los locos son las víctimas individuales por excelencia de la dictadura social. $Y$ en nombre de esa individualidad, que es patrimonio del hombre, reclamamos la libertad de esos galeotes de la sensibilidad, ya que no está dentro de las facultades de la ley el condenar a encierro a todos aquellos que piensan y obran.

Sin insistir en el carácter verdaderamente genial de las manifestaciones de ciertos locos, en la medida de nuestra aptitud para estimarlas, afirmamos la legitimidad absoluta de su concepción de la realidad y de todos los actos que de ella se derivan.

Esperamos que mañana por la mañana, a la hora de la visita médica, recuerden esto, cuando traten de conversar sin léxico con esos hombres sobre los cuales -reconózcanlo- solo tienen la superioridad que da la fuerza. (1967: 31-32)

El autómata, probablemente en coincidencia con estas ideas y con el exasperado ánimo expresado por el surrealista Artaud21, no es un fácil 'elogio de

21 Que luego será expulsado y renunciará, cuando no admita la afiliación al Partido Comunista. Ver, al respecto, su declaración "En plena noche". 
la locura'. Representa, más bien, la dolorosa recusación de la maquinaria social que busca impedir el ejercicio de la libertad constriñendo a los seres humanos a seguir los patrones estrechos de una visión meramente instrumental del individuo. Con Sergio, lo que se representa es el costo máximo de esa pugna, puesto que él extrema la libertad buscada. En él -y sobre todo en su cuerpo agonizante y dislocado, en su imposibilidad de articular los gritos que pugnan por emerger, en el naufragio de sus capacidades sexuales a pesar de su encendido deseo- se escenifica un combate de resonancia colectiva: no uno que competa solamente, entonces, a la sociedad burguesa y al sujeto aprisionado, sino a todos los hombres, incluidos aquellos que, como el padre, se acomodan sin discusiones a una dinámica deshumanizadora y enajenante.

\section{Estética e ideología (II): el cuerpo, el narrador, el mito}

En los párrafos anteriores mencioné que el encierro en el manicomio va destruyendo la vocación transgresora de Sergio y termina matándolo, a lo que añadí esta misma expresión ("termina matándolo") entre signos de interrogación. Esto porque, aunque existe efectivamente el capítulo titulado "Muerte del autómata" en el que se le da por muerto en la primera línea y en varios otros pasajes, a la vez se sigue percibiendo su resistencia a morir, se especula sobre su posibilidad de volverse a reconocer en primera persona o se menciona su desesperación. Podría pensarse, a partir de esa contradicción, en que se nos hace asistir -a los lectores- al extraño tránsito hacia la muerte de Sergio, lo que sellaría el estatuto fantástico del relato insinuado desde las primeras páginas por algunos detalles que van más allá del acercamiento a los laberintos de la (in)conciencia del personaje o del lenguaje figurativo y poético utilizado. Lo que veríamos, entonces, sería al personaje en el tránsito hacia su muerte o actuando y reaccionando después de su muerte. Esta dimensión fantástica se acentúa a continuación, en el capítulo "Metamorfosis de Sergio", en se habla de la profundidad del vacío que es Sergio, pero luego se alude a una suerte de diseminación de su existencia (de su cuerpo, de su ser) que invade todo y puede ser percibida (porque se arraiga en cuerpos y materias) si se tiene la voluntad para lograrlo: "Al fondo vuestro -si lo queréis oídos- sentiréis el desgarrarse lento, hondo, de Sergio, en plantas, en minerales, en dolor de superficie a ciegas" (62); "Lo tenéis aquí en este claro metal que parece ojo sin amor. No os asustéis de su condición. Yo me he acostumbrado a sus cambios de naturaleza en tal forma, que mi vida percibe en igualdad y latido su creación” (64).

En estos capítulos finales -como se observa en las citas- aumentan la automenciones del narrador, que se constituye, de ese modo, a sí mismo como 
protagonista, en una dinámica que oscila entre la evidencia de una conciencia metanarrativa que podría debilitar el 'efecto de realidad' del relato -como es frecuente en la narrativa de vanguardia (Achugar 1996: 26) - y la voluntad de afirmación de la verdad de sus palabras, con lo que la historia parece deslizarse al terreno del testimonio sin que disminuya por eso el componente fantástico de lo narrado:

Ya conocéis sus movimientos. Flujo y reflujo. Su discurrir bajo, lejano en resacas de marea olvidados para el triángulo. ¿Sabéis su posición? Buscadlo. Si yo lo hiciera, él saldría como trompa de mi interior, de entre las venas más dadas a la circulación febril, desesperada.

Todo él -Sergio- va siendo mi intimidad. Una nueva vida en la que todo se abre de naturaleza, de persona, de encanto.

¿Soy yo mismo Sergio, acaso en otro tiempo pasado o por venir? No es esta autopregunta debida a una crisis lógica y meditada, sino más bien a una repentina urgencia sin pecho de aire, de contacto íntimo. (Abril 2008: 64-65).

A la vez, como se ha visto en los fragmentos citados, también han aumentado las apelaciones a los interlocutores o lectores, cuyo sentido parece ser, cada vez más, exhortarlos o invitarlos a abrirse a esa fuerza simultáneamente material e inmaterial que emana de Sergio metamorfoseado. Se trata, entonces, de una invitación a la apertura de la mirada, a la resistencia y a la transformación ("Es aquí preferible el terreno para inquirir y ahondar al ser perdido. No lo olvidéis. Ninguna cobardía os incite al desahucio por el temor de las transformaciones o sorpresas humanas. Escandallar -si es posible- los sótanos del mar en los cuales las bajas resacas arman mitos marinos", 63) que, al dirigirse a una segunda persona plural, involucra como horizonte una dinámica colectiva. Con esto, la desbordada rebelión individual de Sergio, en tanto anárquico héroe del inconformismo y la insatisfacción -al modo de Vaché-, resulta canalizada por el narrador en una perspectiva más constructiva y colectiva que, sin embargo, no implica un optimismo ingenuo, pues descubrir esa fuerza siempre será una tarea dura y peligrosa.

En este punto, es posible regresar ahora a la interrogante planteada páginas atrás: ¿cómo se inscribe El autómata en el tránsito de Xavier Abril desde un vanguardismo antiburgués pero todavía de poca densidad política hacia una convicción declaradamente socialista y revolucionaria? La revisión hecha en este trabajo permite corroborar, en términos generales -aunque con nuevos elementos que, en mi opinión, corresponden a una comprensión más cabal del personaje de Sergio y su condición de autómata- la afirmación de Jorge Valenzuela, quien señala que en la escritura surrealista de este libro "es visible 
la mediación conceptual e ideológica de su fe en el socialismo que busca direccionar el texto hacia el combate social contra el orden burgués" (2008: 22). Pero resulta necesario añadir -aun sea preliminarmente- algunos aspectos que sitúan mejor esta inscripción. El primero es la correspondencia entre la preocupación de Abril -en sus declaraciones y manifiestos revisados de los años 1929 y 30 - por representar los procesos de renovación estético-ideológica y, sobre todo, de transformación histórica hacia una nueva sociedad revolucionaria y socialista y lo que sucede en El autómata con Sergio, enfatizado también, como señalé como un proceso fundamentalmente concerniente al cuerpo, incluso luego de su 'muerte', en que las metamorfosis hacen que se plasme -o que solo sea perceptible- en materialidades diversas.

El segundo, vinculado con las metamorfosis finales de El autómata, se refiere a la dimensión mítica que supone este desenlace, que solo es posible, en la nouvelle, a partir de la confirmación de su estatuto fantástico. La propuesta de un mito como perspectiva -cuando lo que busca Abril, según sus propias declaraciones, es la afirmación de su convicción revolucionaria- resulta sintomática de un momento en que algunas de las mentes más lúcidas del pensamiento socialista, a ambos lados del Atlántico, proponían algo semejante. Por un lado, Mariátegui, en "El hombre y el mito", había señalado en 1925 -y esto debió conocerlo Abril- que, a diferencia de la civilización burguesa, que adolecía de la falta de un mito -puesto que ni la razón ni la ciencia pueden satisfacer por sí solas la necesidad de infinito del ser humano-, el proletariado sí contaba con uno, la revolución social, cuya fuerza es análoga -señala- de la de la fe religiosa. En Europa, por su parte, Walter Benjamin, en un breve ensayo de 1929 titulado "El surrealismo. La última instantánea de la inteligencia europea" -seguramente desconocido, al menos en esos momentos, por Abril-, proponía que los surrealistas eran los únicos que, en ese momento de la historia -en que ellos, por su parte, han sumado sus energías a las del comunismo-, lograban reconocer las exigencias que comporta el desafío propuesto por Marx, porque buscaban "ganar las fuerzas de la ebriedad para la revolución" (1980: 58) y organizar el pesimismo hasta convertirlo en un "pesimismo activo" (Lowy 2007: 86), volcado hacia impedir el advenimiento de lo peor. Dicha ebriedad -explica Michael Lowy (a partir de este y otros textos contemporáneos de Benjamin)representa una propuesta de reencantamiento del mundo, una "iluminación profana” de carácter materialista y antropológico.

No pretendo establecer relaciones causales entre los planteamientos de Mariátegui y Benjamin, por un lado -que, aunque diferentes entre sí, presentan interesantes conexiones- y El autómata de Abril, por otro. Lo que me ha interesado -para terminar esta aproximación a Abril y El autómata en el contexto 
de las reflexiones estético-ideológicas de sus años de escritura- ha sido sugerir cómo Abril, en estos momentos en que todavía no ha abandonado sus convicciones vanguardistas-surrealistas (a pesar de que parece postergarlas en sus declaraciones), busca en su renovadora narrativa una integración que coincide con las preocupaciones por darle una profunda vitalidad al socialismo, a la vez que desarrolla una propuesta de escritura que, simultáneamente, reclamaba un nuevo tipo de lector. Uno que, quizá, compartiera esas mismas búsquedas y preocupaciones.

\section{Referencias bibliográficas}

ABRIL, Xavier (1929a) "Estética del sentido en la crítica nueva”. Amauta 24; pp. 49-52.

ABRIL, Xavier (1929b) "Nota a la muerte de la novela". Amauta 27, pp. 69-70.

ABRIL, Xavier (1930) "Palabras para asegurar una posición dudosa”. Bolívar 12, pp. 6-7. ABRIL, Xavier (1931) Hollywood (Relatos contemporáneos). Madrid: Ediciones Ulises.

ABRIL, Xavier (1993) El autómata, en Narrativa peruana de vanguardia (selección, introducción y notas de J. Kishimoto). Documentos de Literatura 2-3; pp. 159-204.

ABRIL, Xavier (2006) Poesía soñada. Edición de Marco Martos Carrera. Lima: Universidad Nacional Mayor de San Marcos / Academia Peruana de la Lengua / Universidad San Martín de Porres.

ABRIL, Xavier (2008) El autómata y otros relatos. Estudio preliminar de Jorge Valenzuela Garcés. Lima: Pontificia Universidad Católica del Perú.

ACHUGAR, Hugo (ed.) (1996) Narrativa vanguardista hispanoamericana. México: Ediciones del Equilibrista; pp. 7-40.

ARTAUD, Antonin (1967) Carta a los poderes. Buenos Aires: Insurrexit.

BENJAMIN, Walter (1980) "El surrealismo. La última instantánea de la inteligencia europea”. Imaginación y sociedad. Iluminaciones I. Madrid: Taurus; pp. 41-62.

BRETON, André (1928) “De "Les Feuilles Libres»". Amauta 18, p. 84.

BOURDIEU, Pierre (2002) Campo de poder campo intelectual. Buenos Aires: Montessor.

CHUECA, Luis Fernando (ed.) (2009) Poesía vanguardista peruana. Lima: Pontificia Universidad Católica del Perú.

ELGUERA, Christian (2009) "El autómata: la mirada surrealista, la crítica humanista". Espéculo. Revista de estudios literarios 43. 12 de julio 2011. http://www.ucm.es/ info/especulo/numero43/automat.html.

FOUCAULT, Michel (1999) “La locura y la sociedad”. Estética, ética y hermenéutica. Barcelona: Paidós; pp. 73-95.

GONZÁLEZ VIGIL, Ricardo (2004) Poesía peruana vanguardista. Lima: Fondo Editorial Cultura Peruana. 
KISHIMOTO, Jorge (ed.) (1993) Narrativa peruana de vanguardia. Documentos de Literatura 2-3, pp. 9-18.

LAUER, Mirko (2001) Antología de la poesía vanguardista peruana. Lima: Ediciones El Virrey y Hueso Húmero Ediciones.

LAUER, Mirko (2003) Musa Mecánica. Maquinas y poesía en la vanguardia peruana. Lima: Instituto de Estudios Peruanos.

LÓPEZ DEGREGORI, Carlos (2010) “Xavier Abril: la vida perfecta de la locura”, en Chueca et al. Umbrales y márgenes. El poema en prosa en el Perú contemporáneo. Lima: Universidad de Lima; 53-67.

LÓPEZ LENCI, Yazmín (1999) El laboratorio de la vanguardia literaria en el Perú. Lima: Editorial Horizonte.

LOWI, Michael (2007) "Walter Benjamin y el surrealismo: historia de un encantamiento revolucionario”. Acta Poética 28 (1-2), pp.73-92.

MARIÁTEGUI, José Carlos (1988) “El hombre y el mito”. El alma matinal y otras estaciones del hombre de hoy. Lima: Amauta.

SÁNCHEZ, Luis Alberto (1931) “De junio a junio”, en Mundial, p. 30.

VALENZUELA Garcés, Jorge (2008) "Xavier Abril y la experiencia de la vanguardia en El autómata y otros relatos", (estudio preliminar) en El autómata y otros relatos. Lima: Pontificia Universidad Católica del Perú; pp. 7-27.

VERANI, Hugo J (1996) Narrativa vanguardista hispanoamericana. México: Ediciones del Equilibrista.

WESTPHALEN, Emilio Adolfo (1996) Escritos varios sobre arte y poesía. México D.F.: Fondo de Cultura Económica.

ZAVALETA, Carlos Eduardo (2002) El gozo de las letras. Ensayos y artículos, 1952-2001. Lima: Biblioteca Nacional del Perú.

ZAVALETA, Carlos Eduardo (2006) Narradores peruanos de los 50's: Estudio y antología. Lima: Instituto Nacional de Cultura-Centro de Estudios Literarios Antonio Cornejo Polar. 
LETRAS 86 (123), 2015 